\title{
Correction to: The trade-off between economic growth and environmental quality: does economic freedom asymmetric matter for Pakistan?
}

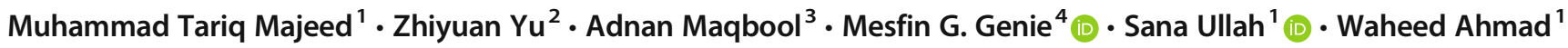 \\ Published online: 4 May 2021 \\ (C) Springer-Verlag GmbH Germany, part of Springer Nature 2021
}

\section{Correction to: Environmental Science and Pollution Research} https://doi.org/10.1007/s11356-021-13709-9

The correct affiliation of Mesfin Genie is presented in this paper.

Publisher's note Springer Nature remains neutral with regard to jurisdictional claims in published maps and institutional affiliations.

The online version of the original article can be found at https://doi.org/ 10.1007/s11356-021-13709-9

Zhiyuan $\mathrm{Yu}$

379460230@qq.com

$\triangle$ Sana Ullah

sana_ullah133@yahoo.com

Muhammad Tariq Majeed

tariq@qau.edu.pk

Adnan Maqbool

adnanpak@yahoo.com

Mesfin G. Genie

mesfin.genie@abdn.ac.uk
Waheed Ahmad

awaheed@eco.qau.edu.pk

1 School of Economics, Quaid-i-Azam University, Islamabad, Pakistan

2 Department of Economics and Management, Taiyuan Institute of Technology, Taiyuan 030008, China

3 Department of Management Sciences, Khwaja Fareed University of Engineering and Information Technology, Rahim Yar Khan, Pakistan

4 Health Economics Research Unit, University of Aberdeen, Aberdeen, UK 